\title{
SUICIDE, HOMICIDE OR BEAR ATTACK?
}

\author{
Nadeera D.R. ${ }^{1}$ \& Gayathree T.H.I. ${ }^{2}$ \\ ${ }^{1}$ General Hospital, Ampara, Sri Lanka \\ ${ }^{2}$ Department of Forensic Medicine, Faculty of Medicine, University of Peradeniya, \\ Sri Lanka.
}

Corresponding author: D.R Nadeera

Email: druchiranadeera@gmail.com https://orcid.org/0000-0002-1525-7445

\section{Introduction}

Discriminating injuries by animal attacks from other types of trauma and assessing their contribution to the cause of death is often difficult. Careful evaluation of the injury pattern, thorough scene examination and performing adequate ancillary investigations is essential in such situations.

\section{Case report}

A young male was found dead in a hut in a chena, lying in a pool of blood with a shotgun beside him. There was a suicide note on the floor written with charcoal which indicated that he had encountered three bears in the jungle, fought and escaped with injuries. Autopsy revealed minimal damage to the clothes and to the body. There was a near contact entry wound under the chin. Shaving of the head hair revealed a star shaped entrance wound with burning and blackening on the vertex. An exit wound with extensive disruption of the left side of face was seen. CT scan confirmed the above findings. The manner of death was concluded as a homicide.

\section{Conclusion}

Minimal damages to the clothes and other areas of the body exclude bear attack with a high probability. Even though entry under the chin is more suggestive of suicidal firing, the entry at the vertex favors the involvement of another person.

Keywords: Bear attack, Homicide, Shotgun

All articles in Sri Lanka Journal of Forensic Medicine, Science \& Law are licensed under the terms of the Creative Commons Attribution-Non Commercial 4.0 International License 


\section{Introduction}

Animals may be responsible for an array of potentially lethal injuries. On occasion, blunt or sharp trauma from animal activity may be confused with postmortem artifacts or with inflicted injury from an assault. ${ }^{1}$ Hence, discriminating injuries by animal attacks that mimic other types of trauma and assessing their contribution to the cause of death is often difficult. Careful evaluation of the injury pattern, thorough scene examination and performing adequate ancillary investigations is essential in such situations.

\section{Case Report}

A 36 year old male attached to the Civil Security Defense Force was found dead in a hut in a chena at a remote area of Ampara, Sri Lanka. He was in a supine position in a pool of blood and a locally made muzzle loading shotgun lay on his left side. There was an extensive ripped injury on the left side of the face. There were multiple footprints stained with the dried blood of an adult human on either side of the body but no blood was seen on the soles of the deceased [Fig. 1]. History revealed that he was a right handed.

There was a scrawl on the cement floor written with wood charcoal, stating that he was attacked by three bears in the jungle, fought and escaped with injuries and decided to commit suicide [Fig.2]

One of the metal sheets of the roof had a circular hole with a small piece of cloth [Fig. 3]. This cloth was smeared with gun powder but had no blood. There were multiple fragments of human tissue in the surrounding area. A bag belonging to the victim was found in an area deep in the jungle about $6 \mathrm{~km}$ away from the chena, with blood and disturbed vegetation.

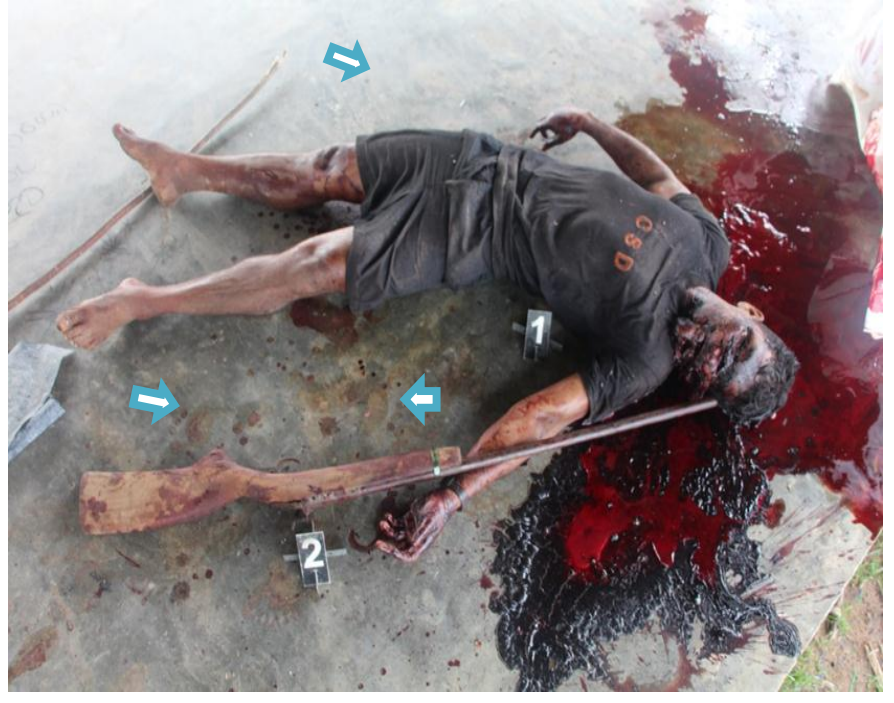

Fig: 1. Position of the dead body and the shotgun. [There were multiple human footprints either side of the body. (Arrows)]

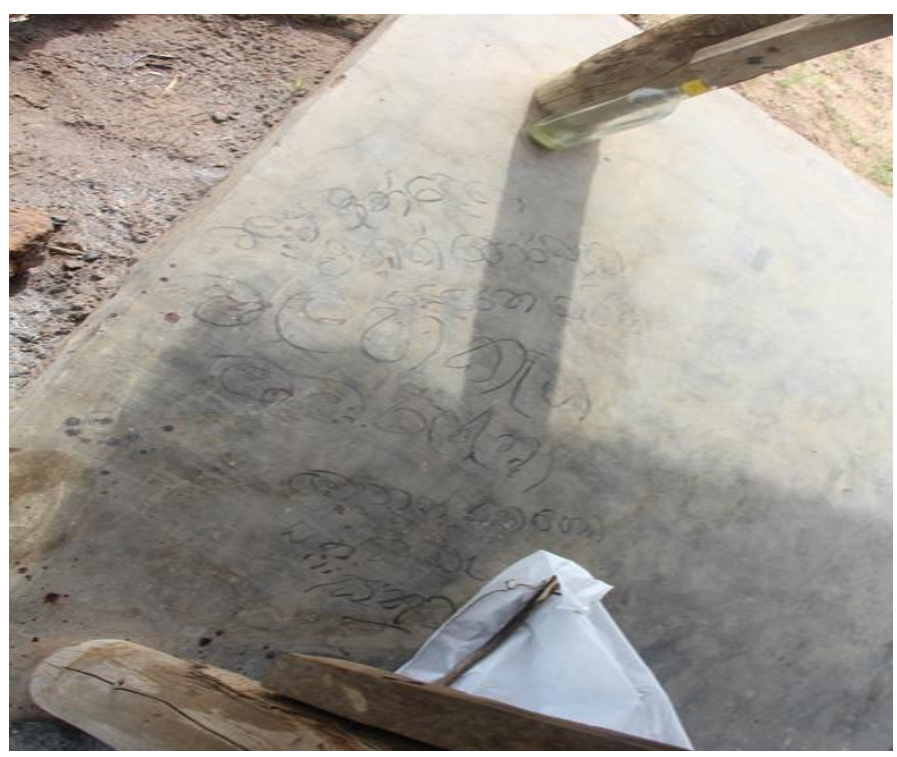

Fig: 2. Suicide note on the floor scribble by wood charcoal 


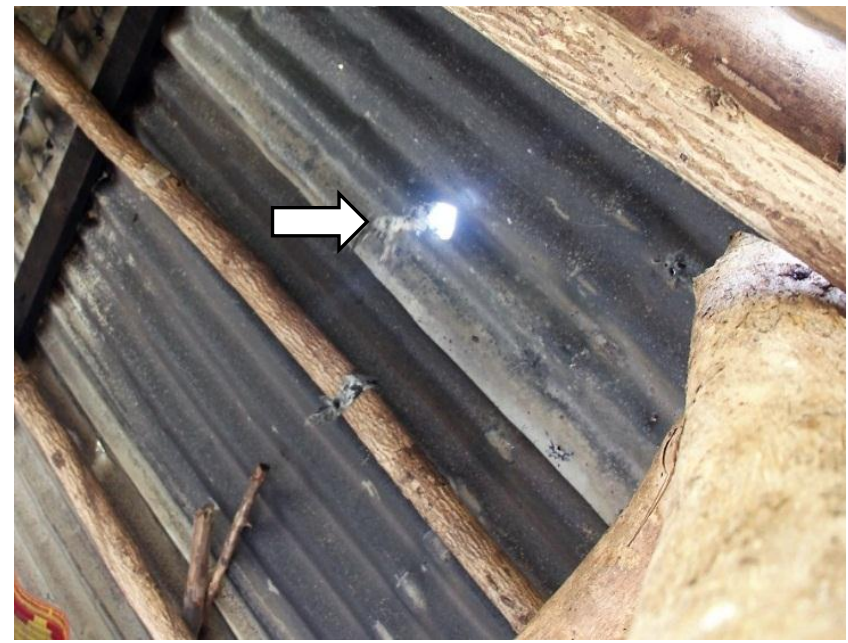

Fig: 3. Hole on the roof with a piece of cloth hanging (arrow).

CT scan was done prior to the autopsy. The pattern of metal pieces and pathway of pneumocephalus [Fig. 4] indicated that the direction of firing was from top of the head to the left side.
Hypostasis was fixed in dependent areas such as on face, sides and front of the neck, trunk and limbs sparing pressure areas which was compatible with the position in which he was found at the scene [Fig. 1]. There was no disturbance to his clothing or injuries to the body below the neck.

The wound under the chin showed burning, blackening and tattooing with perforated laceration which was recognized as an entry wound. The perforated laceration placed on left side of the face showed extensive tissue disruption and resembled an exit wound [Fig.5].

Shaving of the head hair revealed a stellate shaped perforated laceration with burning and blackening placed just posterior to the vertex and associated with deficiency of skull which was circular, $1.5 \mathrm{~cm}$ in diameter and inner beveling. This injury was identified as an entry wound. The exit wound of this injury was placed on same

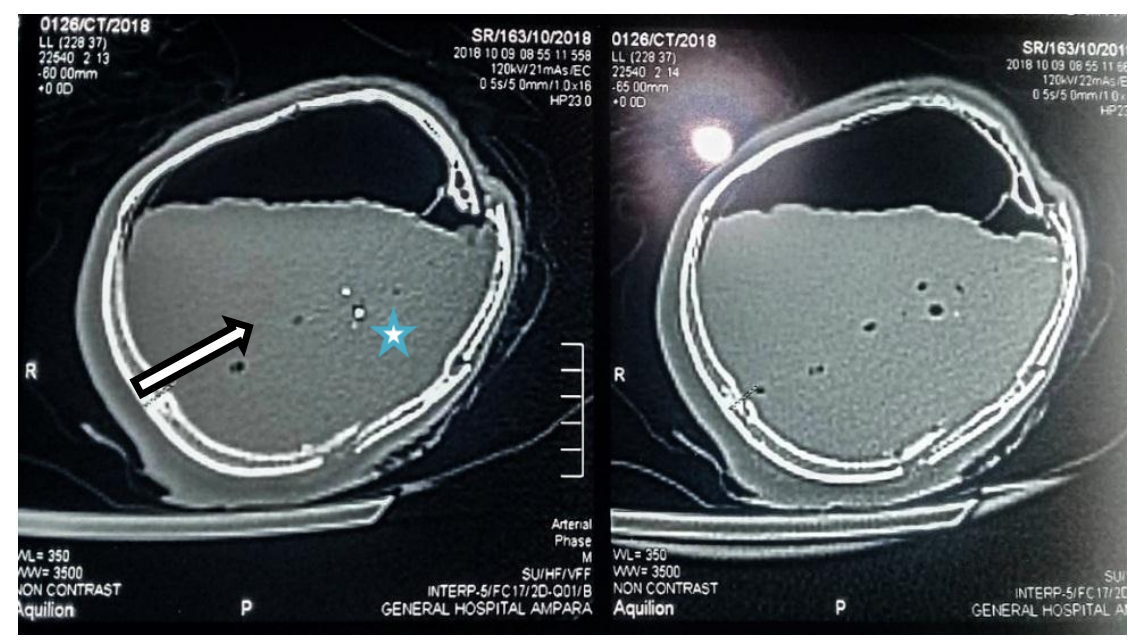

Fig: 4. CT of the head [The section is at the level of vertex in this figure. The position of the head is turned on to the left. There is a pathway of pneumocephalus (arrow) along with two metal pieces $(*)]$.

Autopsy revealed a $70 \mathrm{~kg}$ Asian Caucasoid $178 \mathrm{~cm}$ in height. There was no evidence of physical or congenital deformities. The deceased was clad in a black color T-shirt and a short trouser. exit wound described above [Fig. 6]. The trajectory of this injury was through the brain, injuring the occipital area, mid-brain and left temporal areas.

There were four lacerations measuring 1$3 \mathrm{~cm}$ on the dorsal aspects of both hands similar to defense injuries. The laceration on the middle phalanx of right ring finger exposed an underlying fractured and strands of hair. 


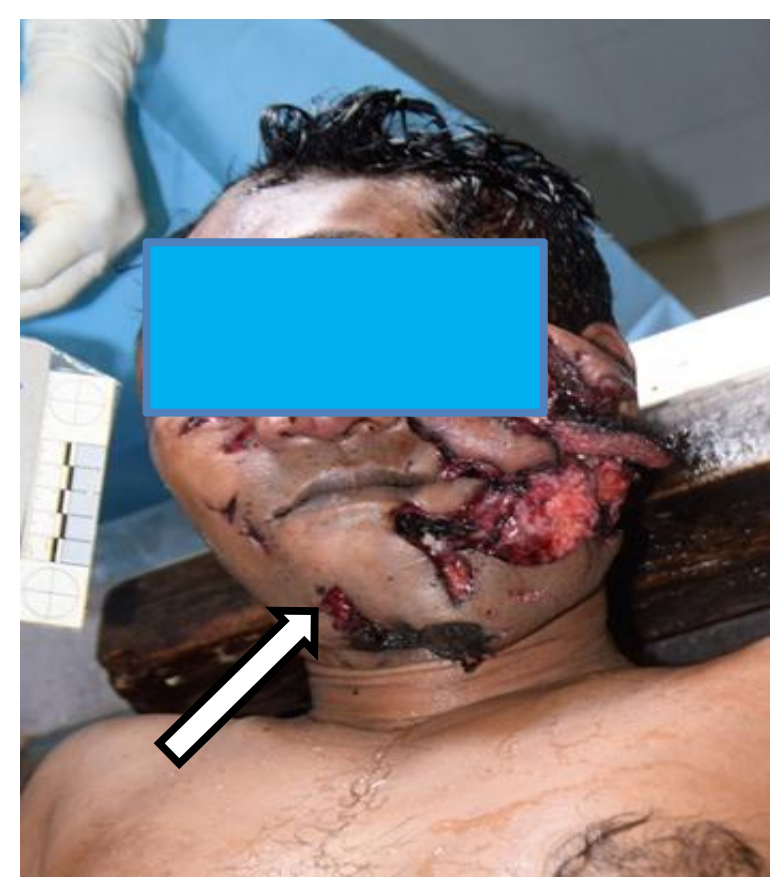

Fig: 5. Shot gun injury to the face. [Arrowentry site and direction upwards and to the left]

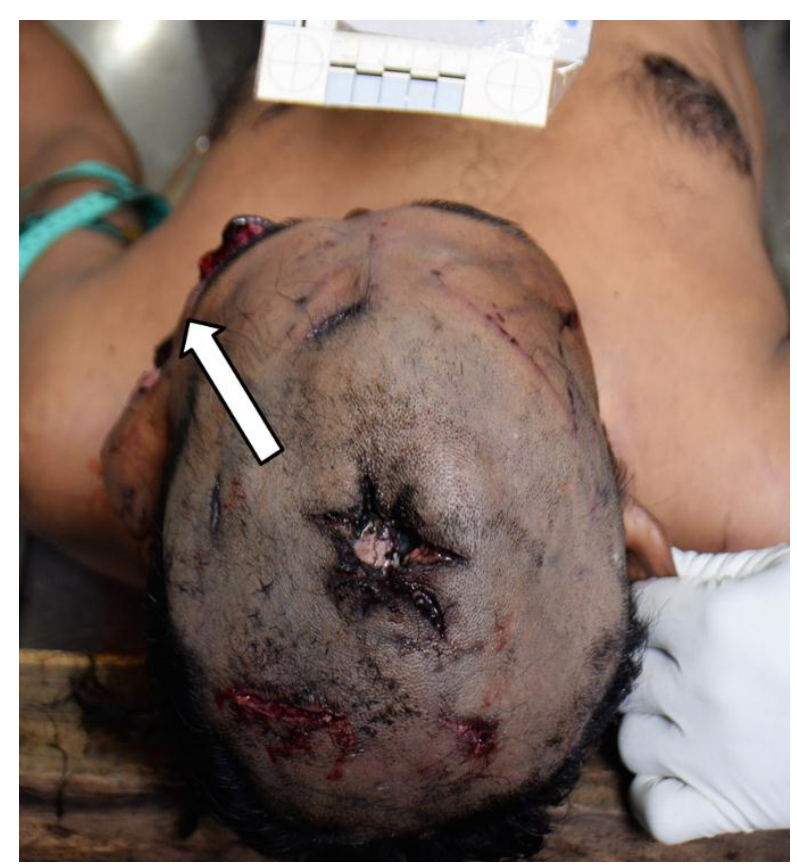

Fig: 6. stellate entry at the vertex [Exit in the same area as shown in fig. 5, Arrowdirection of the shot downwards and to the left]
A blood sample, strand of hair in the finger and the air dried cloth were sent to the Government Analyst (GA) for DNA analysis. Swabs from finger tips and webs, clipped nails from both hands and tissue swabs from two entry wounds were sent to explosive and fire investigation section of the GA department to detect gun powder residues. Hand writing of the deceased was taken from a $\log$ book and sent with a photograph of the scrawl on the floor to the Examination of Question Document section of the GA department. The cause of death was given as firearm injuries to the head and manner was concluded as homicide following the death investigation.

\section{Discussion}

Exit wounds after discharge of smooth bore weapons are quite variable in appearance. At its most extreme, gross catastrophic disruption may be seen. This is especially so in shots in close proximity to the head. ${ }^{2}$ In this case the major injury to the left side of the face was due to the exit wound of a shot gun. The entry was under the chin with features suggestive of near contact range. The injury was compatible with an upwards and to the left direction. Since the deceased was right handed, the direction and the range was compatible with suicide. However, the position of the shot gun placed on the left side aroused the possibility that this was a case of homicide.

A firm contact discharge against tissue overlying bone (such as the skull) causes gas to rebound from the rigid base raising a dome under the skin that can split to give a ragged entrance wound. This effect is by no means invariable. ${ }^{3} \mathrm{~A}$ similar entry was found on the top of the head in this case. The range can be determined as firm contact according to the described nature of the entry as above. CT scan of the head confirmed the pathway of shrapnel or missile / a bullet from vertex to the left side of the face, hence a common exit to both entries. Since the site of the entry on the 
head was inaccessible, it indicated firing by another person.

It was impossible to determine whether a shrapnel from the gunshot under the chin caused injuries to the brain as there was another gunshot to the head. Therefore, possibility of volitional activities after the shot under the chin cannot be determined. However, there was a high possibility of ruling out volitional activity after the shot to the head as it causes gross destruction to the brain.

Bear attacks with paws, claws and teeth cause tearing, crushing, cutting and penetrating injuries to the body. ${ }^{4}$ They stand on hind limbs and attack with fore limbs, usually to the upper part of human body. Human beings show a natural reflex action of covering the face using upper limbs while being attacked. This reflex action makes injuries of upper limbs a common presentation. ${ }^{5}$ In this case, the scribble on the floor stated that the deceased encountered three bears and fought them.

Defense wounds are caused when a victim attempts to protect himself from an attacker and indicates that this victim is conscious at that moment. ${ }^{6}$

Defense injuries found on the body were mainly superficial lacerations over the dorsum of both hands and a compound fracture of the right middle phalanx of the ring finger and this pattern is compatible with previous studies as well. $7,8,9$

At the same time there were minimal injuries to the rest of the body and minimally damaged clothes.

Scene examination is very important, especially in abnormal presentation of deaths due to asphyxia and firearms ${ }^{10,11,}$ $12,13,14$ and assists in reconstructing event. If the deceased fought with three bears, as per the suicidal note, there would have been more injuries to the body than what was found. Therefore, it aroused suspicion of an actual bears attack. Also the pattern of injuries were such that the possibility of defense injuries due to human attack could not be excluded. With the compound fracture of a finger in the dominant hand one must expect a fair amount of blood where the suicidal note was written. However, this was not so. Therefore, there was a high chance that the scrawl was by another person to mislead the circumstance of death.

The human foot print at a scene of crime is valuable physical evidence. ${ }^{15}$ However, absence of blood on the soles of the deceased implied that one or more people walked around the body after the incident. Analysis of foot prints would help trace the assailants. ${ }^{16,17,18}$

A hole on the roof with a piece of cloth smeared with gun powder but no blood is more in favor of a shot which was had not gone through the body. As the shot gun at the scene was a muzzle loading gun, the probability of a second shot from the decedent after sustain the injury to the head is very remote.

\section{Conclusion}

Thorough scene examination, careful evaluation of the injury pattern and adequate ancillary investigations in this case indicated that the circumstance of death is more favor of homicide than suicide.

\section{References}

01. Bury D, Langlois N, Byard RW. Animal-related fatalities-part I: Characteristic autopsy findings and variable causes of death associated with blunt and sharp trauma. Journal of forensic sciences. 2012; 57(2): 370-4. DOI:10.1111/j.15564029.2011.01921.x 
02. Dodd MJ. Terminal ballistics: a text and atlas of gunshot wounds. Crc Press; 2005. DOI:10.1201/9781420037463

03. Gilyoma JM, Mabula JB, Chalya PL. Animal-related injuries in a resource-limited setting: experiences from a Tertiary health institution in northwestern Tanzania. World Journal of Emergency Surgery. 2013; 8(1): 7. DOI:10.1186/1749-7922-8-7

04. Bhat TA, Gulzar A, Bhat AA, Bhat TA, Ali Z. A review of upper limb injuries in bear maul victims: Consistent pattern and inverse relation in severity with facial and scalp injuries. Chinese journal of traumatology. 2018; 21(1): 38-41. DOI:10.1016/j.cjtee.2017.11.001

05. O'Donovan S, Langlois NE, Byard RW. "Defense" type wounds in suicide. Forensic Science, Medicine and Pathology. 2018: 1-4. DOI:10.1007/s12024018-9957-y

06. Brunel C, Fermanian C, Durigon M, de la Grandmaison GL. Homicidal and suicidal sharp force fatalities: autopsy parameters in relation to the manner of death. Forensic science international. 2010; 198(1-3): 150-4. DOI:10.1016/j.forsciint.2010.02.0 17

07. Schmidt U. Sharp force injuries in "clinical" forensic medicine. Forensic science international. 2010; 195(1-3): 1-5.
DOI:10.1016/j.forsciint.2009.10.0 31

08. Vassalini M, Verzeletti A, De Ferrari F. Sharp force injury fatalities: a retrospective study (1982-2012) in Brescia (Italy). Journal of forensic sciences. 2014; 59(6): 1568-74. DOI:10.1111/1556-4029.12487

09. Vadysinghe A, Dassanayake P, Wickramasinghe M. Unusual case of suicide with a modified trap gun. The American journal of forensic medicine and pathology. 2017; 38(2): 97-9. DOI: 10.1097/PAF.0000000000000302

10. Vadysinghe

AN, Sivasubramanium M, Jayasooriya RP. A tree branch instead of a ligature: an unusual accidental hanging. Forensic Science, Medicine and Pathology. 2017; 13(4): 441-3. DOI: 10.1007/s 12024-017-99025

11. Vadysinghe AN, Sivasubramanium M. Anesthetized by chloroform before hanging. Forensic Science, Medicine and Pathology. 2018: 15. DOI:10.1007/s12024-0189974-x

12. Thejaswi HT, Kumar A, Krishna K. Significance of crime scene visit by forensic pathologist in cases of atypical firearm injuries. Kathmandu University Medical Journal. 2015; 51(3): 272-6.

13. Kunz SN, Meyer HJ, Kraus S. Forensic aspects of gunshot suicides in Germany. Wiener 
medizinische Wochenschrift (1946). 2013; 163(23-24): 541-8. DOI: $10.1007 / \mathrm{s} 10354-013-0227-\mathrm{z}$

14. Osisanwo FY, Adetunmbi AO, Alese BK. Forensic analysis and the inimitability of human footprints. International Journal of Intelligent Computing Research. 2015; 6(1): 527-30.

15. Kennedy RB. Uniqueness of bare feet and its use as a possible means of identification. Forensic science international. 1996; 82(1): 81-7.

DOI:10.1016/0379-

0738(96)01969-X

16. Abbott JR, Germann AC, Springfield IL, Adach E, Knapp W, Adair TW. Shoe, Foot, and Tire Impression Evidence. Pathology.; 29: 136-40.

17. Bodziak WJ. Footwear impression evidence: detection, recovery and examination. CRC Press; 2017. DOI:10.1201/9780203755587 